\title{
"Así se Baila el Tango": milongueros, políticas y campeonatos de baile en la ciudad de Buenos Aires ${ }^{1}$
}

\author{
Hernán Morel $^{2}$ \\ Universidad de Buenos Aires, Argentina \\ E-mail: hermorel@hotmail.com
}


Resumo

No presente artigo propomos analisar a dança social do tango a partir dos campeonatos oficiais de dança que se realizam na cidade de Buenos Aires. Estes campeonatos, eventos culturais públicos de grande envergadura, têm procurado pôr em cena as artes performativas que caracterizam a dança dos "milongueros" portenhos. Por meio das legitimações e noções sustentadas pelos atores envolvidos nestes certames, abordamos o modo em que estas ações oficiais tendem a criar uma areia de debate público sobre a dança bem como incidem na formação e a valorização das tradições de dança.

Palavras-chave: Tango. Campeonatos. Políticas. Performance. Dança.

\section{Abstract}

In this paper, we analyze the social dance of tango since the inception of the official dancing competitions in the city of Buenos Aires. These championships, huge public cultural events, have sought to bring to the stage the performing art which characterizes the dance of the "milonga" and local "milongueros". Through legitimation and the notions of authenticity which the involved actors invoke in such events, we address the issue of how these official measures tend to spark public debate on the dance itself and their effects on the formation and appreciation of dance traditions.

Keywords: Tango. Championships. Policies. Performance. Dance. 


\section{Introducción}

耳 $\mathrm{n}$ el presente artículo proponemos pensar el baile de tango en confluencia con una serie de procesos de activación patrimonial e intervención oficial manifiestos a comienzos del nuevo milenio en la ciudad de Buenos Aires. Estos procesos serán analizados prestando especial atención en la danza social del tango y su relación con un conjunto de nuevas políticas culturales vinculadas a la realización de campeonatos oficiales de baile. Dichos campeonatos, en tanto eventos culturales públicos de gran envergadura, aspiran a poner en escena las artes performativas que caracterizan al baile de los "milongueros" y "milongueras"3 porteños.

De modo que sobre la base del contexto de los campeonatos buscamos abordar el estudio de la danza social del tango considerando no sólo el rol de las políticas estatales en los procesos de reconfiguración sino también las formas de construcción y apropiación social que involucran a los propios performers implicados en la producción de prácticas y sentidos en torno al baile (REED, 1998). En particular, a través de las legitimaciones y las nociones de autenticidad que sostienen los actores involucrados en estos certámenes, abordamos el modo en que estas acciones oficiales tienden a crear una arena de debate público sobre el baile así como inciden en la formación emergente y la valorización de tradiciones dancísticas; que implican al mismo tiempo, procesos de selección, depuración y omisión de determinados aspectos del baile. Si bien, como veremos, estas novedosas iniciativas del Estado local tendieron a inscribir al baile social dentro de una lógica de mayor espectacularización, el rol de los bailarines y jurados de tango tuvo una influencia significativa al momento de delinear determinados 
sentidos, parámetros y valores de autenticidad deseable, modelando las habilidades, destrezas y aptitudes necesarias de los performers. En tal sentido, analizamos cómo los actores involucrados negocian y disputan sus identificaciones con el baile a través de formas de legitimación que suponen la reivindicación de determinadas trayectorias, modos de aprendizaje y espacios de formación en el tango social. A partir del modo en que se legitiman como continuadores de un "legado", examinamos la manera en que los bailarines acentúan un "origen común" seleccionando y utilizando estratégicamente elementos de un pasado significativo para dotar de valor a las prácticas del presente. Sobre la base de algunas de las concepciones que acompañaron a este proceso de legitimación intentamos problematizar un conjunto de prácticas narrativas y cinéticas que tienden a naturalizar, establecer propiedades intrínsecas y crear nociones de autenticidad en relación al baile ${ }^{4}$.

La información y los datos sobre los cuales este trabajo se basa provienen de una etnografía que incluyó la observación de distintas instancias del campeonato, tomar clases con diferentes profesores así como participar de milongas y eventos de danza de diversa índole vinculados con el baile social del tango ${ }^{5}$. En términos metodológicos, la etnografía que realizamos atendió de manera conjunta las relaciones entre aspectos cinéticos y verbales referidos a la danza, buscando conocer las categorizaciones y los sentidos locales que le otorgan al baile social de tango los actores participantes, sobre la base de una actuación en contextos específicos y como parte de una comunicación culturalmente situada ${ }^{6}$. Cabe subrayar que en las últimas décadas, la antropología de la danza ha tendido a interrelacionarse con los estudios de performance y las teorías sobre la corporeidad (CAROZZI, 2011; CITRO, 2012). En lo que se refiere a la influencia de los estudios de performance, estos han destacado la importancia del contexto inmediato (evento) en que se producen e inscriben las performances, así como han centrado su atención en los diversos modos de evaluación que esgrimen los miembros de comunidades competentes, indagando en las relaciones dialógicas entre lo representado, los intérpretes y las audiencias. A su vez, los estudios de performance, enfocando su atención en las prácticas culturales que contextualizan tradiciones al 
tiempo presente (MARTÍN, 2005), han enfatizado cómo los sujetos y grupos sociales construyen sus prácticas como parte de un devenir histórico que va configurando y dotando de autoridad a ciertas formas, funciones y sentidos de las performances (BAUMAN y BRIGGS, 1996).

A través de un análisis de los procesos, los contextos y las agencias involucradas en la creación de criterios y valores de autenticidad en torno al baile social del tango que se ejecuta en los campeonatos, nos interesa conocer, ¿en qué consisten estos criterios de autenticidad? ¿cómo y en qué contextos algunos actores enfatizan que sus formas de baile están asociadas a un pasado local? ¿quiénes tienen poder/ autoridad para definir límites y parámetros en el baile social del tango? Por lo pronto, comencemos haciendo una breve descripción de los campeonatos y del contexto en que se inscriben las políticas culturales ligadas al tango en Buenos Aires.

\section{Los Campeonatos Metropolitanos y Mundiales de Baile}

Desde hace más de una década se organizan, dentro de la agenda cultural oficial de la ciudad de Buenos Aires, eventos de gran envergadura bajo la forma de festivales y campeonatos de baile de tango. Por su parte, en el año 1998 el Gobierno de la Ciudad crea un Festival de tango, mientras que a partir de los años 2002 y 2003 se instauran dos campeonatos de baile, uno Metropolitano y otro Mundial. Estos certámenes de baile, al igual que el festival de tango, se realizan con una periodicidad anual, aunque con el transcurso del tiempo fueron modificando sus fechas, lugares y modalidades de realización. Para dar una noción de estos eventos, a continuación realizamos una breve descripción de las características organizativas y los cambios que acompañaron al proceso de implementación de estos campeonatos, desde el momento de su creación hasta el año 2010.

En un primer momento, tanto el Campeonato Metropolitano, cuanto el Mundial fueron concebidos como eventos estrechamente vinculados al calendario del Festival de Tango. Así, el primer Campeonato Metropolitano de tango, denominando por única vez como "Campeonato de Tango de Salón con Estilo y Elegancia" se realizó entre enero y febrero del año 2002, cerrando su actividad en el marco 
del Festival de Tango ${ }^{7}$. A su vez, al año siguiente se realizó el primer Campeonato Mundial durante el mes de marzo de 2003, también como una actividad integrada al propio Festival de Tango ${ }^{8}$. Ambos campeonatos constan de distintas rondas eliminatorias que se dividen en tres etapas: clasificatorias, semifinales y finales. En lo referido a la categoría de tango salón, las rondas eliminatorias del primer Campeonato Mundial transcurrieron en el Centro Cultural San Martín, mientras que la competencia final se realizó en el Estadio de Obras Sanitarias ${ }^{9}$.

Ahora bien, desde el año 2005 al 2010 el Campeonato Metropolitano de baile seguirá realizándose -variando según el año- entre los meses de abril y julio. Respecto a las rondas clasificatorias, ellas continuarán desarrollándose en distintas milongas de la ciudad ${ }^{10}$, en tanto, las rondas finales, que son las que convocan más público, irán modificando sus sedes según el año ${ }^{11}$. En referencia a lo acontecido en el Campeonato Mundial, entre el año 2005 y 2007 éste se organiza en el Predio de la Rural. A partir del año 2008, el Campeonato Mundial vuelve a hacerse conjuntamente con el Festival de Tango (aunque ya en el mes de agosto), teniendo como sede central las galerías Harrods. Durante ese mismo año, la ronda final de la categoría de tango salón ocurre en el Estadio de Obras Sanitarias, y a partir del año 2009, se hará en el estadio Luna Park.

Como podemos observar, un hecho a destacar es que estos campeonatos se valen tanto de la descentralización como de la centralización. Por un lado, las primeras rondas clasificatorias y las semifinales del Campeonato Metropolitano suceden "dentro" del circuito de milongas que funcionan de modo permanente en la ciudad, mientras que el Mundial es antecedido tanto por preclasificatorias (que se organizan en distintas sedes del interior y el exterior del país), como por las rondas clasificatorias y semifinales (que se realizan durante la semana misma que antecede a la ronda final en distintas sedes). A su vez, a diferencia del Campeonato Mundial que se efectúa en sedes especialmente montadas para la ocasión, el Metropolitano se desarrolla mayormente en las pistas de las milongas, por lo que la actividad de este último suele integrarse a la dinámica consuetudinaria de los habitúes de la milonga ${ }^{12}$. Por otro lado, tanto las rondas finales del 
Metropolitano como las del Campeonato Mundial se caracterizan por ser eventos centralizados en estadios o predios de gran envergadura y capacidad de público. Sustentados en el montaje de una enorme infraestructura organizativa, estos eventos espectacularizados dirigen la atención del público concurrente en torno a un gran escenario, el cual es acompañado por pantallas gigantes que replican imágenes de lo que ocurre sobre el mismo.

En general, para los concursantes bailarines que compiten en estos eventos, las exigencias, el esfuerzo y las expectativas que implican participar de los mismos son muy grandes. Destaquemos que estos campeonatos son de participación libre y gratuita por lo que pueden inscribirse ${ }^{13}$ tanto parejas aficionadas como profesionales. En lo que atiene a las categorías de baile que reconoce cada uno de estos certámenes, si bien el Mundial ${ }^{14}$ incluye dos (tango salón y escenario), el Metropolitano con el correr de los años fue sumando otras ${ }^{15}$. En referencia a sus modalidades organizativas, si bien estos campeonatos dependen de la Secretaría de Cultura del Gobierno de la Ciudad, será la Asociación de Maestros, Bailarines y Coreógrafos de Tango Argentino ${ }^{16}$ (AMBCTA) la principal organización designada para el asesoramiento, la elección de jurados y el diseño del reglamento a seguir por las parejas participantes. En cuanto a la categoría de "tango salón", los criterios serán similares tanto para el Campeonato Metropolitano, como para el Mundial. El reglamento del Campeonato Mundial 2009 explicita los siguientes puntos:

- La pareja, una vez conformada, no podrá separarse mientras dure la música. Esto significa que no se podrá romper el abrazo, considerado como la posición de danza del tango;

-Para que la posición sea considerada correcta, el cuerpo de uno de los integrantes de la pareja debe estar contenido, todo el tiempo, por el abrazo del otro, entendiéndose que -en determinadas figuras- esto puede ser elástico; pero no en toda la duración de la danza;

- Todos los movimientos deberán ser realizados dentro del espacio que permita el abrazo entre los que conforman la pareja;

- El Jurado tomará en cuenta la musicalidad y el estilo al caminar como puntos fundamentales para la calificación; 
- Dentro de estos parámetros de observación, se podrán realizar todas las figuras que son de uso popular, incluyéndose barridas, sacadas al piso, enrosques, etc;

- Quedan completamente excluidos los ganchos, saltos, trepadas y cualquier otra posibilidad coreográfica propia del Tango Escenario;

- Las parejas, como en el salón de baile, deberán trasladarse constantemente en el sentido contrario al que siguen las agujas del reloj, no pudiendo demorarse en un mismo punto del espacio coreográfico ya que esto entorpecería la circulación de la ronda de baile;

-Ninguno de los integrantes de la pareja podrá levantar las piernas más allá de la línea de las rodillas.

En particular, la categoría de "tango salón" busca reflejar el baile social de tango tal como se realiza en las pistas de las milongas porteñas. Por sobre todo, es en esta categoría en donde se afianza la idea de un baile auténticamente porteño, aquel que se practica asiduamente en las pistas de las milongas. Como menciona el reglamento, allí prima un baile "al piso" y sin "ruptura del abrazo", quedando prohibidas la realización de grandes figuras, acrobacias y saltos asociados al tango escénico. En la práctica, la modalidad de competencia de estos certámenes establece que bailen simultáneamente un número aproximado de diez parejas por ronda. Estas parejas deben circular por el borde de la pista (o escenario) desplazándose en el sentido contrario a las agujas del reloj. A su vez, la ronda que bailan los performers está musicalizada por tres grabaciones de tangos de orquestas tradicionales, cada una representativa de distintos estilos rítmicos y sonoridades musicales ${ }^{17}$.

Ahora bien, más allá de la explicitación de estos parámetros formales, ¿de qué manera se aplican dichos criterios desde el punto de vista de los competidores y jurados?; ¿sobre la base de qué parámetros se discierne el "buen baile"?; ¿cómo interpretan los propios participantes de la competencia estas descripciones y requerimientos presentes en el reglamento? En principio, consideremos las relaciones entre autenticidad y criterios de "buen baile" que construyen y sostienen los asiduos concurrentes de las milongas porteñas. 


\section{La Autenticidad de los "Viejos Milongueros"}

A partir del reciente estreno de un documental ${ }^{18}$, en el cual participan algunos destacados milongueros y milongueras de Buenos Aires, se publicó una nota periodística en la que se califica a las personas mayores que lo protagonizan como poseedoras de un "arte detenido en el tiempo". Curiosamente, a pesar de que estos bailarines populares en el pasado eran mal vistos, con el paso del tiempo se han convertido en los personajes más elogiados y renombrados dentro del mundo de las milongas porteñas, e incluso más allá de las fronteras nacionales:

Si en alguna época el término "milonguero" fue un insulto, hoy es poco menos que un título de nobleza. La palabra nombra al bailarín de tango formado en los clubes de barrio durante las décadas del ' 40 y '50. Tipos de no muy buena fama en aquel entonces, vagos según una opinión establecida, dedicaban la tarde a practicar pasos y ocupaban la noche en frecuentar las pistas de baile. Pero con el correr del tiempo y el resurgimiento y expansión del tango en escala planetaria, los milongueros sobrevivientes comenzaron a gozar de prestigio y respeto: hoy son maestros muy buscados, codiciados compañeros de baile, fuentes de sabiduría. (Diario Clarín, sección Espectáculos, 03/05/2013)

Frecuentemente, dentro de los ámbitos de las milongas tradicionales de Buenos Aires suele decirse que el "mejor nivel de baile" lo tienen aquellos que, de manera coloquial, son llamados "viejos milongueros". Distintos autores consideraron este carácter sobresaliente, así como el valor simbólico concedido a estos milongueros antiguos en virtud del singular prestigio con el que son reconocidos dentro de la escena de los salones de baile porteños (SAVIGLIANO, 1995; PUJOL, 1999). Estos hombres son apreciados como poseedores de un baile inigualable, que supone complejas habilidades y saberes que ni los varones más jóvenes, ni los hombres de distintas edades que han ingresado al circuito de baile más recientemente poseen en igual medida que los más antiguos. En particular, algunos aspectos de esta asociación entre "buen baile" y edad avanzada de los bailarines fueron analizados por Carozzi (2005) a partir de una etnografía enfocada en 
las milongas céntricas de la ciudad. La autora señala las expectativas que manifiestan las mujeres por bailar con estos hombres añosos, en vistas al enorme placer que le transmite su baile, y a que el logro de esta meta implica para ellas un avance en la jerarquía del "nivel" de baile que existe dentro de la milonga. Así, desde el punto de vista de las aspiraciones femeninas, la cúspide de esta jerarquía consiste en ser invitadas a bailar, o más aún, ser compañeras de baile de estos experimentados milongueros, en especial aquellos que se consideran los más "auténticos" en virtud de haber vivido las llamadas décadas de "oro" del tango que se ubican entre las décadas del ' 40 y el '50. Por su parte, los hombres más jóvenes o nuevos, que ingresan al circuito de baile, reafirmarán estos mismos criterios justificando que la calidad del "buen baile" que detentan los milongueros antiguos, depende de sus años de permanencia en la milonga y de los "kilómetros" de pista que tienen "caminados". A su vez, legitimando esta visión dominante, los jóvenes o nuevos performers enfatizarán su trayectoria en el baile, diciendo haber aprendido "estando" y "mirando" en la milonga a los milongueros añosos; ocultando así el hecho de haber tomado clases para no ser acusados como bailarines de "academia" (CAROZZI, 2005).

Ahora bien, este reconocimiento del "buen nivel de baile" conferido a los milongueros más antiguos, no solo se reproduce y legitima dentro de los espacios de baile de las milongas, sino que también tuvo un rol significativo dentro del contexto mismo de los campeonatos. En relación a ello, un matutino destaca a qué apuntó el primer Campeonato Metropolitano de baile:

[...]se pensó en recuperar aquellos antiguos campeonatos de baile de salón, donde brillaban los milongueros de las décadas del 30, 40 y 50, maestros de la sutileza como Pepito Avellaneda, Gerardo Portalea, Pupi Castello y el Tete, entre otros. Con ese espíritu de antaño y para incentivar el semillero que hace rato crece en todas las milongas de la ciudad[...] (Diario La Nación, sección Espectáculos, 04/01/2002)

Advertimos que, ya desde un primer momento, los campeonatos tendrán como propósito principal "recuperar" no sólo una antigua práctica asociada a las modalidades de baile de los "milongueros de 
antes", sino también estimular la participación de un "semillero" de nuevos danzantes que se han volcado en los últimos años al baile social del tango. Más específicamente, a través de la categoría "tango salón" se buscará plasmar los movimientos, estilos, formas de desplazarse y de caminar con "naturalidad" que realizan tanto los milongueros mayores como los más jóvenes en las pistas de baile porteñas.

No obstante ello, la puesta en marcha de los campeonatos planteó algunas interpretaciones disímiles en torno a la cuestión etaria de los concursantes. Por un lado, a pesar de la gran diferencia de edad entre los participantes del campeonato -que cubre un rango desde los 18 hasta más de 70 años- durante las primeras ediciones de estos certámenes oficiales, las parejas que arribarán al podio del primer puesto estarán representadas mayoritariamente por milongueros aficionados de edad avanzada. A partir de sus particulares formas y estilos de baile, estos milongueros maduros saldrán nuevamente al ruedo, orgullosos de mostrar sus pasos y habilidades, así como de "medirse" con los ágiles cuerpos de los bailarines jóvenes. Un matutino afirma acerca de los ganadores del Campeonato Metropolitano 2004:

Delia Nasra y Lito Filipini, los ganadores, tienen 70 y 76 años, respectivamente. (...). Hace cuarenta años que bailan juntos, y en su casa tienen armado un museo privado de tango con fotos, películas y grabaciones históricas que fueron juntando con el tiempo. Ella pasó de la danza clásica al tango. Él aprendió, dice, "en la escuela de la vida": "De jovencitos practicábamos en las esquinas del barrio, y los fines de semana íbamos a los bailes a sacar pasos". Filipini tiene muy en claro por dónde pasan las diferencias generacionales: "Los pibes jóvenes son un mimbre. Hacen pasos muy estudiados, y a veces les juegan a favor los cuerpos. Nosotros sabemos vestir bien, y tenemos mucha pista en cada paso. ¿Quién nos quita lo bailado?" (Diario Página 12, sección Espectáculos, 09/03/2004)

En general, los milongueros mayores legitimarán verbalmente el dominio superior de su performance frente a la de los jóvenes, argumentado que ellos bailan un "sentimiento" propio que "no se adquiere de golpe", sino que sólo viene "con el paso del tiempo". En otras pa- 
labras, esgrimirán que el "buen baile", el más genuino y auténtico, el que evidencia su más acabado ajuste con lo que transmite la música se adquiere sólo a través de la experiencia de los años. Al hacerlo, desestiman la agilidad en los movimientos, el dominio de "precisión técnica" y el "estudio" que suele caracterizar a las nuevas generaciones. Como señalará "Puppi" -uno de estos afamados milongueros- quien a través de un relato referido a un "nosotros" del pasado, construye al presente como su revés degradado:

[...]Ahora los pibes vienen para triunfar arriba de un escenario y no porque sientan tanto el tango. Nosotros pedíamos de 10 centavos para juntar para la entrada al baile. A nosotros nos gustaba el tango de verdad. Pero ahora es otra cosa (Diario La Nación, sección Espectáculos, 27/07/2004)

De todos modos, a pesar de la gran diferencia de edad entre los milongueros mayores y los más jóvenes, durante los primeros campeonatos, muchos jurados sostenían que no era necesario que los participantes concursaran en rubros separados dado que:

"No es un problema de luchas entre generaciones, sino de bailar bien o mal. Cuando alguien tiene calidad se reconoce inmediatamente, tenga la edad que tenga", dice Naveira. "De hecho, en las milongas se mezcla gente de todas las edades. Si el tango no discrimina, ¿por qué lo vamos a hacer nosotros?", razona Rivarola (Diario Página 12, sección Espectáculos, 09/03/2004)

Como vemos hasta aquí, en un primer momento, estos campeonatos pasaron a ser un incentivo para la participación tanto de jóvenes bailarines aficionados y profesionales, como para algunos milongueros mayores que se animaban a participar de este nuevo desafío hacia el final de sus vidas. Ahora bien, esta presunción, de que los mayores "bailan mejor" que los bailarines jóvenes, irá revirtiéndose en el transcurso de unos pocos años. Así, si por un lado desde los años 2002 a 2004 todas las parejas ganadoras en la categoría de tango salón serán de edad avanzada, a partir del año 2006 pasarán a llegar a las finales mayoritariamente parejas de chicos jóvenes, arribando precisamente éstos a los primeros puestos ${ }^{19}$. No obstante, esta especie de dicotomía 
que plantean los milongueros mayores, entre la "técnica" de los jóvenes y el "sentimiento" de aquellos que "peinan canas", seguirá siendo un tópico discursivo muy presente a la hora de evaluar las performances de los jóvenes bailarines, como lo esgrimirá un reconocido bailarín, milonguero y jurado de estos certámenes:

[...]Cuando empezaron los concursos, estos por lo general ganaban gente mayor y bueno, ahora los mayores que bailan bien ya ganaron. Entonces ahora aparecen los nuevos bailarines con mucho estudio, con mucha técnica, que solamente podemos detectar nosotros que a veces le falta la cosa del sentimiento que tiene la gente mayor y contra de eso tienen la elegancia, tienen la postura, la cosa que da la juventud, la estética que da la juventud [...] nosotros que tenemos la experiencia de lo que es el baile sabemos que la forma de tomarse, la forma de pisar, la forma de avanzar, la forma de sentir la música hace que eso tenga un punto más importante en el sentimiento, y el chico que recién está diríamos comenzando va a estar estéticamente mejor parado, va a estar más elegante [...] es técnica y siempre le va a faltar eso que se logra con el tiempo, no es que no lo va a poder hacer, sino que eso se va haciendo, se madura." (Eduardo Arquimbau, entrevista en el programa de radio Fractura Expuesta, 02/06/08, nuestro énfasis).

Vemos que a partir de estos certámenes de baile se crean arenas y espacios de conflicto en torno a quiénes se consideran, en términos etarios, como idóneos y competentes al momento para transmitir una "buena" performance de baile. Advertimos en los relatos que esta disputa, además de tener un correlato generacional, aparece atravesada por una tendencia que va desde el baile aficionado y amateur -característico en los milongueros mayores-, hasta una práctica vinculada con personas profesionalizadas o semiprofesionalizadas (que dan clases, hacen exhibiciones, actúan en espectáculos) que; en muchos casos, incluyen no solo una formación didáctica estrechamente emparentada con el estudio de "técnicas" afines a las artes escénicas modernas en relación al tango; sino también provenientes de otras danzas (clásica, contemporánea, folklórica, etc.).

Sobre la base de lo dicho hasta aquí, señalamos que las diversas formas de baile social del tango tendieron a organizarse jerárquica- 
mente y a evaluarse dentro de los campeonatos, de un modo bastante semejante a cómo se concebía el "buen nivel de baile" dentro de las milongas porteñas. En función a ello, en un primer momento, la puesta en marcha de los campeonatos planteó como expectativa principal "recuperar", homenajear y reconocer el arte de los milongueros mayores. En efecto, en el marco de esta coyuntura, durante los primeros años, los bailarines más jóvenes debieron lidiar con ciertas restricciones. Sin embargo, y pese a estos condicionamientos que reafirman y celebran algunos aspectos del orden convencional y "ortodoxo" que rige en las milongas, ciertos cambios se irán introduciendo a partir de las nuevas posibilidades de exhibición que instaló el campeonato, consolidándose como un lugar de oportunidades para el lucimiento de las nuevas camadas de performers.

\section{Genealogías Milongueras: de maestros y sucesores}

En el año 2007, Dante Sánchez e Inés Muzzopappa (él tenía 19 y ella 20 años) ganaron el primer premio en la categoría de tango salón del Campeonato Mundial. En aquel momento, Dante - luego de ser condecorado y ante un público masivo de miles de personas- agradeció primero a sus "maestros" Carlos y Rosa Pérez ${ }^{20}$, y luego sobre el escenario y frente al micrófono dijo:

Este premio está dedicado a los milongueros viejos, a los que realmente bailan tango, a los que vivieron la época del ' 40 y el '50. Pienso que se está perdiendo el verdadero tango de salón, porque se está bailando de una forma muy moderna y se está perdiendo el abrazo del tango, que es lo más importante.

En el marco de una actuación exitosa por parte de esta pareja de jóvenes bailarines dentro del campeonato, el relato inmediato que esgrimió Dante para legitimar aquel logro, implicó la reafirmación de una tradición local frente a una supuesta modernización que entiende, estaría "desvirtuando" al baile del tango salón. Vemos así que la idea de "pérdida" del baile tradicional no sólo será verbalizada por aquellos milongueros mayores, sino que también será explicitada dentro de los campeonatos por los bailarines jóvenes. De modo que 
sustentando una retórica que lamenta la pérdida de autenticidad en el baile, las nuevas encarnaciones de milongueros que participan de los campeonatos, buscarán recuperar y reinstaurar las formas expresivas de los "milongueros viejos".

Cabe destacar que en la mayoría de los casos, estos bailarines jóvenes que participan de los campeonatos afirmarán haber sido formados e influenciados por algunos "maestros milongueros", en especial aquellos más proclives a determinados criterios visuales para la evaluación del baile ${ }^{21}$. Así, a pesar que se observe efectivamente en el campeonato un mayor predominio "técnico", asociado a una estética visual en la que se valora la "precisión", la "prolijidad" o el "virtuosismo" en los movimientos, estos bailarines jóvenes destacarán que sus conocimientos y habilidades corporales provienen de haber sido "entrenados" por milongueros antiguos. Estos milongueros serán aquellos que bailaron en las llamadas "décadas de oro del tango" y que hoy promedian los setenta o más años de edad o, en ciertos casos, algunas personas de generación intermedia que han tenido una relación directa con estos milongueros añosos y sus particulares formas de baile. A través de una transmisión y aprendizaje personal con estos milongueros mayores, las nuevas generaciones irán asociando sus performances actuales con un estilo de baile ${ }^{22}$, que será connotándolo como el más apropiado para ser recontextualizado en la escena de los campeonatos, una forma de baile característica que afirman, proviene del barrio porteño de Villa Urquiza ${ }^{23}$.

En este sentido serán las nuevas camadas de jóvenes, que arriban a los primeros puestos del Campeonato Metropolitano y Mundial, quienes se verán particularmente identificados con esta tradición de baile social asociada a los milongueros y a las milongas de la zona de Villa Urquiza y alrededores ${ }^{24}$. ¿De qué manera los practicantes identificados con este estilo construyen una autoridad tradicional en torno a esta forma de baile? En relación a ello, en una página de internet se argumenta sobre este estilo diciendo:

Debido a que en tiempos anteriores uno podía ver estilos de baile diferente dependiendo del barrio al que uno iba a bailar o al cual pertenecía, se fueron creando formas o sub estilos en el Tango Salón como, por ejemplo, el 
estilo Villa Urquiza, entre otros. Aun cuando aquellos mismo que "representan" el estilo Villa Urquiza dicen que no existe tal estilo, se dice que la gente de este barrio posee más elegancia, realiza pasos más largos, que el foco está en la melodía, es un baile más pausado y que tiene un conocimiento mayor del baile. Los siguientes bailarines son famosos en este "estilo": Gerardo Portalea (fallecido), "Finito" Ramón Rivera (fallecido), "Lampazo" José Vázquez (fallecido), "El Turco" José Brahemcha (fallecido), Miguel Angel Zotto y Milena Plebs, El Chino Perico, Jorge Díspari y la Turca, Javier Rodríguez y Andrea Misse, y la familia Misse. (http://www.estilotangosalon. com/estilostango.php)

La forma de baile que algunos denominan como Villa Urquiza fue construyéndose como marcador estilístico a partir de los relatos y las referencias a los milongueros ${ }^{25}$, que suelen (o solían) frecuentar los bailes que se realizan en los clubes sociales y deportivos de este barrio. En general, el modo en que se narra esta historia por parte de las nuevas generaciones coincide en trazar una construcción genealógica que implica recurrir al pasado para trazar continuidades que los vinculen con el presente. Estas continuidades entre miembros de distintas generaciones se organizan a partir de una ubicación genealógica, que identifica a ciertos "fundadores" de las generaciones anteriores como "maestros" y a las nuevas generaciones de bailarines como sus "sucesores" o "herederos". La importancia y el valor concedido a estos "maestros" proviene de haber sido ellos quienes han mantenido, transmitido y enseñado aquellas formas particulares, así como ciertos "secretos" de este estilo de baile, a las nuevas generaciones.

No obstante, como se explicita en la cita mencionada arriba, si bien existen algunos acuerdos generales sobre aquellos bailarines que "representan" al estilo, frecuentemente la inclusión o exclusión de determinados milongueros y milongueras dentro de una genealogía unificada produce contrariedades y discrepancias de distinta índole. Estas discusiones no solo ocurren entre integrantes de distintas generaciones, sino que también se manifiestan entre los miembros de una misma generación. Por ejemplo, existen casos en que algunos miembros de las generaciones de los "maestros" no se auto-reconocen 
como parte de este estilo, e incluso en ocasiones, niegan la existencia de este estilo de baile barrial como tal. En otras circunstancias, algunos de los "sucesores" acentúan las influencias y los vínculos personales que han tenido con alguien que consideran, fue su "maestro" (sea de la misma generación o de una generación anterior), mientras que la persona aludida como "maestro" afirma, o bien no haberle enseñado, o bien no reconocerlo como un "sucesor". Así, frecuentemente circulan dentro de estos ámbitos milongueros anécdotas "desacreditadoras" que buscan desmentir relatos contados por algún bailarín/a que nombró haber aprendido, mantenido una relación cercana o considerarse "sucesor" de algún "maestro" de una generación previa. Como observó Bourdieu (1999, p. 90), muchas veces el acto de nombrar a alguien o nominar algo (un estilo de baile, una persona reconocida) pretende producir e imponer un orden en el mundo social.

Por otra parte, la construcción discursiva de este estilo de baile barrial aparecerá ligada a determinados tiempos, lugares y personas significativas. En especial, la fuente de procedencia del estilo suele asociarse a referentes milongueros fallecidos en las últimas décadas. Generalmente, estos suelen ser descriptos como en la siguiente nota, en la que se realiza un homenaje a "Finito", un afamado milonguero fallecido a fines de la década del ‘80:

¡Cuántos bailarines actuales, dueños de una técnica mecánica, pero sin que el corazón les baje a los pies, deberían aprender! O no. Esas cosas no se aprenden; se llevan adentro. Porque Finito era un milonguero de patio, ni más ni menos que un milonguero de patio. Esto significa que nunca vivió del baile sino de su oficio de mecánico. A propósito de los milongueros de patio (...) el mejor bailarín de tango es el milonguero anónimo. Es decir, él que era sólo conocido en su barrio y quizá, poco más allá, y con el tiempo, su nombre quedaba en el olvido. (Revista Tras Cartón Barrio y Cultura, Mayo 2012)

Véase cómo estos milongueros barriales, antes bailarines aficionados y "anónimos", pasan ahora a ser "héroes populares" que se consagran como máxima expresión de naturalidad y autenticidad del tango salón. Caracterizados como aquellos "milongueros de patio" de antaño, estos precursores del estilo serán venerados como sujetos irrepetibles, 
contraponiéndolos al carácter inauténtico de los modernos bailarines, estigmatizados como excesivamente técnicos, artificiales e incluso comerciales. Interpelados por estas construcciones de autenticidad, la estrategia de los bailarines y profesores de tango, cuya trayectoria de inicio en el baile se retrotrae a las últimas décadas, tenderá a reproducir a esta ortodoxia milonguera ${ }^{26}$. Como podemos advertir, sobre la base de estos "legendarios" milongueros se irá construyendo en las últimas décadas algo así como un pasado "mítico", que los consagra encarnando "el" ideal de autenticidad y fidelidad del tango salón.

En síntesis, a partir de distintas narrativas que fuimos señalando, observamos la preponderancia de una idea de origen común que permite incrementar el sentido de identidad compartida de ciertos milongueros y bailarines, a través de una retórica de la descendencia que los vincula con ciertos ancestros o "maestros". Como observa Brow, esta idea fortalece "[...] la convicción de que lo que vincula a un grupo de gente no es solamente/exactamente un pasado compartido, sino un origen común" (2000, p.25). A su vez, la exaltación de ciertas figuras milongueras antiguas y su identificación con un territorio permite construir una versión del pasado que no solamente liga a ciertos milongueros unos con otros por medio de proclamar una descendencia compartida, sino que también los asocia como un todo que se inscribe dentro de un territorio primordial; representado por los "patios" y los "clubes sociales" de barrio. Todas estas representaciones del pasado permiten establecer una idea de carácter perdurable en torno a este estilo de baile en el presente, a pesar de las opiniones discrepantes que, como mencionamos, algunos miembros manifiestan.

\section{Nuevos Actores y Estrategias en las Performances del Campeonato}

Hasta aquí, destacamos un conjunto de relatos que tratan de fundamentar criterios de autenticidad en el baile social del tango sobre la base de modos de construcción de autoridad, que se legitiman en ciertos aspectos y elementos tradicionales. Sin embargo, como también pudimos advertir -a partir de las evaluaciones que esgrimen los "viejos milongueros" respecto a las formas de baile de los jóvenes- "las nuevas 
camadas", con el paso de los años, fueron adquiriendo un rol y un protagonismo importante en la reconfiguración de las performances que se exhiben dentro de los campeonatos.

Tengamos en cuenta que para los concursantes de estos certámenes adecuar lo que "se hace" en las milongas, salones y clubes sociales a un contexto de competencia fuertemente escenificado, exigirá cada vez más a los jóvenes performers un grado mayor de experiencia y entrenamiento en "técnicas" asociadas a una estética de virtuosismo escénico y visual. De este modo, si por un lado, para "mostrarse" algunos tenderán a ejecutar muchos giros, figuras y secuencias vistosas con el ánimo de poder lucirse visualmente frente al jurado y el público presente, por otro, distintos concursantes desplegarán estrategias más sutiles en la búsqueda de mayor eficacia en un contexto cada vez más exigente y competitivo. En este sentido Daniel Nacucchio, campeón Metropolitano y Mundial de tango salón del año 2008, relata las estrategias que utilizó para llamar la atención de los jurados y diferenciarse de los demás competidores durante el certamen:

[...]Entonces vos imagináte [sic] que pasaba esto, está el jurado acá sentado, y pasan adelante de él y todos quieren hacer pasos, y el tipo está cansado de ver pasos, ya lo vio, no quiere que le vengas a mostrar eso, porque le cae mal, le cae mal en la milonga [también] que te vengan a hacer pasos ahí adelante. (...) Entonces yo sé dónde tengo que hacer los pasos, en un lugar estratégico en la pista. Después hay otra cosa, están todos caminando lento, pausado, pero arranca la variación [de la música] y se vuelven todos locos, son todos fieras atadas. Vos tenés diez parejas y hay nueve girando como loco y hay uno que sigue caminando, y vos lo mirás y se te van los ojos ahí porque están todos corriendo, y uno que no. [Y el jurado se pregunta] Si ese sabe tirar [pasos], ¿Por qué no tira?, y a último momento saco uno de la galera, que me enseñó mi profesor y le llegué más al corazón, ¿entendés? Porque es uno que ya no se ve, pero que es muy viejo, viste y está bueno. $\underline{Y}$ lo meto con la música, obviamente, claro. Entonces decís, eso está mucho más rescatado que todo los demás, entonces esa era una técnica, un as bajo la manga. No es porque yo no pueda hacer todo lo que hacen los demás, ni que todos los demás no puedan hacer lo que yo hice, sino que yo sabía lo que estaba haciendo, 
sabía cuando lo iba hacer. Sabía que eran tres tipos de tangos diferentes, que no me iban a poner tres tangos así nomás. Que iba a ser uno rápido, uno mediano y uno lento, uno va a ser romántico o dramático, uno va a ser casi canyengue y el otro iba a ser movidito, para que cada uno se luzca con su estilo de baile. Y para ser campeón tenía que poder manejar esos tres tipos de baile. En el más viejo casi no iba a girar, no la iba a hacer cruzar [a la mujer], era más acompañar la música con el cuerpo, en el lento tenía cosas delicadas como agujas o giros suaves, lentos, buscando el contratiempo, buscando el medio tiempo, haciendo las pausas de la música, y en el rapidito y sí mostrando un poco más de poder, ¿viste? si me mando a un enrosque, me mando bien, pero cerraba con la música, empezaba con la música, era otra cosa. $\underline{\mathrm{O}}$ $\underline{\text { sea, vas entendiendo que hay cosas que están bien vistas }}$ y cosas que están mal vistas en un campeonato, porque es muy subjetivo, entonces, él que comete menos errores es él que puntaje más alto tiene[...] (Entrevista personal, $16 / 12 / 2008)$.

Transcribimos esta larga entextualización para hacer notar el grado de sofisticación que supone la performance de esta danza social dentro de un marco de competencia escenificado. Según el relato, la modalidad de baile que destaca como adecuada para "obtener mayor puntaje" en los campeonatos, requiere tener no solo condiciones aptas de espontaneidad, habilidad y destreza corporal, sino que presupone el conocimiento y la correcta puesta en acto de un capital cultural incorporado, asociado a un amplio espectro de recursos o variaciones de movimientos: un uso sumamente competente de ciertos pasos y secuencias -apelando incluso a "pasos poco conocidos" -, sincronizaciones musicales, agudas evaluaciones del espacio circundante, así como pericia y conocimiento en la interpretación de los distintos ritmos/estilos orquestales que se evalúan en el certamen. A su vez, del relato se desprende la existencia de un conocimiento específico dentro del contexto del certamen, un saber que se construye a partir de la propia situación y de las experiencias de campeonatos anteriores: qué es lo que usualmente hacen los otros competidores en cada parte para diferenciarse, qué les molesta a los jurados, cómo complacer al mayor 
número de ellos y cómo llamar su atención para que la performance los sorprenda de un modo positivo.

Si bien como muchos jóvenes destacan, el baile que ellos ejecutan es representativo de un estilo tradicional, advertimos cómo al mismo tiempo su puesta en acto conlleva prácticas creativas, dinámicas y emergentes que no necesariamente los delimita a ser una mímesis de los milongueros antiguos asociados a este estilo. En este sentido los estudios de performance han señalado permanentemente el carácter paradojal de toda actuación, como observa Schechner, "[ ]debo añadir que todo género de performance y toda instancia particular de un género es concreta, específica y diferente de todas las demás. Es la paradoja fundamental de la performance para que cada instancia sea diferente de las otras, mientras que teóricamente la idea misma de perfomance se basa en la repetición y la restauración. Pero ninguna repetición es exactamente lo que copia; los sistemas están en flujo constante." (2000, p. 13). En el caso del contexto del campeonato, la recontextualización de la práctica social del baile a nuevas situaciones de exhibición, que involucran espacios de mayor envergadura y de escala más espectacular, implicará que los performers desplieguen nuevas estrategias que les permitan conmover y atraer la aguda mirada de los jurados, del mismo modo que influyan en la atención del público masivo que asiste a estos eventos.

\section{Conclusiones}

En este trabajo abordamos el proceso por el cual, al mismo tiempo que se iban estableciendo y poniendo en marcha los campeonatos oficiales de baile, se fue consolidando un debate público en torno a la autenticidad de los performers que participan del mismo, y la legitimidad de las formas de baile que allí se exhiben. Destacamos cómo- a partir del particular prestigio y valor simbólico delegado en los "viejos milongueros" para el imaginario contemporáneo- ciertos grupos de bailarines y profesores reivindicarán ser herederos de las formas de baile de estos reconocidos milongueros. Buscando posicionarse a través del empleo de la tradición como recurso, impulsarán la idea de un estilo de baile al que denominarán Villa Urquiza, denominación que 
transportará y recortará dentro de sí conexiones significativas con un pasado que se actualiza y resignifica a partir de un contexto ubicado en el presente (BAUMANN y BRIGGS, 1996).

Cabe advertir que estas estrategias de autentificación suponen un juego tenso entre autoridad tradicional y creatividad. Por su partecomo observamos- los criterios de autenticidad que suelen esgrimirseremiten a la autoridad delegada por los milongueros antiguos ${ }^{27}$; de manera tal que los jóvenes tenderán a ocultar o minimizar los procesos innovadores y dialógicos que experimenta el baile a partir -por ejemplo- de la influencia de otros estilos de baile de tango, otros géneros dancísticos y distintas instancias de aprendizaje que se inscriben como parte de su trayectoria de formación. No obstante, vimos que sobre la base de una descontextualización y una recodificación funcional del baile, que lo transforma en una performance divorciada del ámbito participativo y social de la milonga, los nuevos performers que participan del campeonato irán innovando en algunas de sus estrategias, habilidades y competencias con el fin de provocar una evaluación positiva por parte del jurado y el auditorio. En síntesis, problematizando los reduccionismos y los estereotipos dominantes que suelen definir a los estilos y las formas de baile social como compartimentos estancos (aislados, estables y unificados), observamos algunas estrategias que construyen los actores buscando defender, negociar o ganar posiciones frente a la aparición de nuevos contextos para la ejecución del baile.

\section{Notas:}

1 Una versión anterior de este trabajo fue presentada en la "X Reunión de Antropología del MERCOSUR (RAM)" en julio de 2013 y publicada en las actas del evento.

2 Dr. en Antropología, investigador asistente de CONICET (Consejo Nacional de Investigaciones Científicas y Técnicas), docente en la carrera de Ciencias Antropológicas de la Facultad de Filosofía y Letras, Universidad de Buenos Aires.

3 Denominación que se utiliza para referirse a las personas que son asiduas concurrentes a la milonga. Por milonga nos referimos al espacio físico en donde la gente se reúne a bailar tango (así como se bailan en menor medida otros géneros musicales como la milonga propiamente, el tango vals y en ocasiones también folklore, tropical, entre otras músicas).

4 En lo referido a estas problemáticas, buscamos combatir la tendencia a pensar el mundo social del baile de un modo substancialista, por lo que lo abordamos en términos de relaciones, como espacios de relaciones sociales (BOURDIEU y WACQUANT, 1995). 
“Así se Baila el Tango": milongueros, políticas y campeonatos de baile en la ciudad de Buenos...

5 Comencé a investigar y a realizar trabajo de campo a partir del año 2006, a la luz de un proyecto de investigación doctoral en el que analicé las políticas y los procesos de activación patrimonial del tango y el carnaval en la ciudad de Buenos Aires. Principalmente, me aboqué al análisis de las performances del tango salón en el marco de los campeonatos oficiales de baile que se realizan en Buenos Aires.

6 Para una reflexión sobre las relaciones de movimiento corporal y lenguaje hablado ver Carozzi (2011).

7 Dicho certamen ocurrió en 35 milongas distribuidas en tres zonas de la ciudad que se dividieron en Centro-Sur, Oeste y Norte, en donde los participantes compitieron en una única categoría denominada "tango salón". Este primer campeonato metropolitano de tango salón contempló como parejas ganadoras a las tres mejores parejas de cada una de estas tres zonas. Este criterio de "campeones por zonas" no volvió a repetirse en los campeonatos posteriores.

8 Señalemos que, a diferencia del Metropolitano, el Campeonato Mundial creó dos categorías: tango salón y tango escenario.

9 Ya para el segundo Campeonato Metropolitano del año 2004, las rondas clasificatorias se organizaron en distintas milongas asignadas para el certamen, mientras que la competencia final se realizó en el Estadio de Obras Sanitarias en marzo, dentro del marco del Festival de Tango. En la segunda edición del Campeonato Mundial del año 2004, a diferencia del año anterior, el evento pasó a organizarse de forma independiente al Festival, concretándose en el Estadio de Obras Sanitarias durante el mes de agosto. A partir de esa fecha, el mes de agosto quedará fijado en la agenda del Campeonato Mundial hasta la actualidad.

${ }^{10}$ El número de milongas que participan del Campeonato Metropolitano oscilará entre 30 y 40 .

11 Situadas en grandes predios como el Espacio Dorrego (2005), en La Rural (2006 y 2007), en el Salón Sur (2008) o en el teatro de un colegio privado (2009 y 2010).

12 De este modo, es frecuente que durante las rondas clasificatorias, las personas que asisten a estas milongas también tomen allí mismo alguna clase de baile (cuando las hay) o bailen en la pista de la milonga, para luego ver o participar del campeonato.

13 Para los que compiten y participan del Campeonato Metropolitano, éste representa el evento más importante en Buenos Aires luego del Mundial, teniendo en cuenta además que los finalistas del primero preclasifican directamente para las finales o semifinales del segundo. Para poder inscribirse al Metropolitano, uno de los miembros de la pareja debe residir en la ciudad de Buenos Aires, mientras que para participar del Mundial las parejas deben inscribirse representando su ciudad de origen.

${ }^{14}$ La cantidad aproximada de parejas que se inscriben suele promediar en un número de 400 para el Campeonato Mundial y de 600 para el Metropolitano. Con respecto a las premiaciones, el campeonato otorga a la pareja que haya arribado al primer puesto una suma en dinero. Por ejemplo, para el año 2009 la categoría de tango salón del Metropolitano otorga \$10.000 y el Mundial, \$15.000.

15 Así, a partir del año 2006 se agrega a la categoría ya existente de "tango salón" la categoría "milonga", mientras que en el año 2009 se incorpora la categoría de "vals".

${ }^{16}$ Dicha Asociación Civil, constituida en el año 2001, será la principal entidad que en la actualidad conglomerará a los artistas afines a esta actividad, así como impulsa, asesora y coopera permanentemente con la organización de eventos oficiales, entre ellos los campeonatos de baile. 
17 A modo de ejemplo, una ronda de tres temas puede incluir orquestas típicas como las de D'Arienzo, Di Sarli y Pugliese.

18 Este documental, llamado "Milongueros" (dirigido por Alejandro Cervera), fue presentado durante abril del año 2013 en el Centro Cultural Ricardo Rojas.

19 Dada la asimetría manifiesta que comenzó a evidenciarse entre los participantes que se presentaban a estos certámenes, a partir del año 2008 la categoría tango salón pasará a estar subdividida por rangos de edad dentro del Campeonato Metropolitano (Adultos y Seniors), aunque ello no será modificado en el Campeonato Mundial.

20 Los Pérez organizan una "práctica", a la que asisten muchos de los bailarines jóvenes que participan del campeonato, en el Club Social y Deportivo Sunderland, sito en el barrio de Villa Urquiza. Señalemos que el Club Sunderland realiza una milonga los días sábados y es frecuentemente identificado como uno de los espacios de baile más tradicionales de Buenos Aires.

${ }^{21}$ Es importante mencionar que existen ciertos estilos de baile, como por ejemplo, el llamado "milonguero", en que las evaluaciones del "buen baile" atienden más a la percepción de "cómo se siente" que al hecho de "cómo se ve".

22 En la actualidad, dentro del baile social existen múltiples formas o estilos dancísticos conviviendo simultáneamente (algunos con denominaciones propias como el "estilo" milonguero, salón, nuevo, canyengue) del mismo modo que cada "estilo" de baile es internamente heterogéneo (MOREL, 2011).

23 El barrio de Villa Urquiza se ubica en la zona norte de la Ciudad de Buenos Aires.

${ }^{24}$ Dentro de las distintas formas de baile social del tango, el llamado estilo de baile Villa Urquiza en los últimos años en Buenos Aires (aunque también en el extranjero) ha venido ganando un singular prestigio. En especial, este estilo de baile fue adquiriendo repercusión a partir de la aparición y puesta en marcha de los campeonatos oficiales de tango salón que se realizan en la ciudad, amén que el mencionado estilo ya era aludido por algunos milongueros y bailarines con anterioridad a estos certámenes. Por su parte, como hemos señalado en trabajos anteriores (MOREL, 2011), las narrativas que refieren a este estilo tradicional de baile reiteran ciertos elementos significativos entre los que se incluyen: el temporal -haberse creado en la "época de oro", el espacial -los clubes sociales y familiares del barrio, las genealogías -los milongueros antiguos y actúales que lo representan y los rasgos característicos -patrones de posturas, movimientos, figuras, etc.

${ }^{25}$ Cabe destacar que en los relatos se destacan los aportes de las figuras masculinas en la formación de este estilo, imperando un punto de vista "masculinocéntrico". A partir de esta distinción de género, frecuentemente son hombres los que se nombran como "fundadores" del estilo.

${ }^{26}$ Estas formas de construcción de autoridad también se observan en relación a otros estilos de baile, más ligados a la zona del centro de la ciudad, en el cual mencionar a los "antiguos" delega cierta legitimidad a profesores y alumnos más nuevos, posesionándose estratégicamente en una jerarquía en donde los antiguos milongueros se ubican "[...]como los últimos creadores del tango y como la encarnación de la ortodoxia, en tanto las nuevas generaciones se forman en la reproducción de sus creaciones." (CAROZZI, 2005, p. 84)

27 Particularmente, esta estrategia tradicionalizadora contrasta con el denominado "tango nuevo" (identificado a bailarines como Gustavo Naviera, "Chicho" Frúmboli y Fabián Salas), quienes en base a posesionarse como actores creadores se ubican en una actitud de ruptura con ciertos órdenes y códigos preestablecidos en el baile tradicional. 


\section{Referencias}

BAUMAN, Richard; BRIGGS, Charles. Género, intertextualidad y poder social. Revista de Investigaciones Folclóricas, N.11, 1996, p. 78-108.

BOURDIEU, Pierre. ¿Qué significa hablar? Economía de los intercambios lingüísticos. Madrid: Akal, 1999.

BOURDIEU, Pierre; WACQUANT, Loïc. Respuestas por una Antropología reflexiva. México: Grijalbo, 1995.

BROW, James. Notas sobre la comunidad, hegemonía y los usos del pasado. En: Fichas de cátedra de Etnolingüistica. El habla en interacción: la comunidad. Buenos Aires: Ed. FFyL/UBA, 2000, p. 21-32.

CAROZZI, María Julia. La edad avanzada como valor en el tango bailado en Buenos Aires. Revista Cuestiones Sociales y Económicas, N. 6, 2005, p. 73-86.

CAROZZI, María Julia. Introducción. En: CAROZZI, María Julia (coord.). Las palabras y los pasos: Etnografías de la danza en la ciudad. Buenos Aires: Gorla, 2011, p. 7-45.

CITRO, Silvia. Cuando escribimos y bailamos. Genealogías y propuestas teórico metodológicas para una antropología de y desde las danzas. En: CITRO, Silvia; ASCHIERI, Patricia (Coord.). Cuerpos en movimiento. Antropologías de y desde las danzas. Buenos Aires: Biblos, 2012, p. 17-64.

MARTIN, Alicia. Introducción. En MARTIN, Alicia (comp.). Folklore en las grandes ciudades. Arte popular, Identidad y Cultura. Buenos Aires: el Zorzal, 2005, p. 7-16.

MOREL, Hernán. Estilos de baile en el tango salón: una aproximación a través de sus evaluaciones verbales. En: CAROZZI, María Julia (coord.). Las palabras y los pasos: Etnografías de la danza en la ciudad. Buenos Aires: Gorla, 2011, p. 190-222.

PUJOL, Sergio. Historia del baile. Buenos Aires: Emecé, 1999.

REED, Susan.The Politics and Poetics of Dance. Annual Review of Anthropology, n. 27, 1998, p. 503-532.

SCHECHNER, Richard. Performance. Teoría y Prácticas interculturales. Buenos Aires: Libros del Rojas, 2000.

SAVIGLIANO, Marta. Tango and the Political Economy of Passion. Boulder: Westview, 1995.

Recebido em 30/07/2013

Aceito em 26/08/2013 